\title{
Major Modes of Short-Term Climate Variability in the Newly Developed NUIST Earth System Model (NESM)
}

\author{
CAO Jian ${ }^{1,2,3}$, Bin WANG ${ }^{1,2,3,4}$, Baoqiang XIANG*5 ${ }^{* 5}$ Juan $\mathrm{LI}^{3}$, WU Tianjie ${ }^{1,2,3}$, \\ Xiouhua $\mathrm{FU}^{1,2,3}$, WU Liguang ${ }^{1,2}$, and MIN Jinzhong ${ }^{1,2}$ \\ ${ }^{1}$ Earth System Modeling Center, Nanjing University of Information Science and Technology, Nanjing 210044 \\ ${ }^{2}$ Key Laboratory of Meteorological Disaster of Ministry of Education, \\ Nanjing University of Information Science and Technology, Nanjing 210044 \\ ${ }^{3}$ International Pacific Research Center, University of Hawaii at Manoa, Honolulu, HI 96822, USA \\ ${ }^{4}$ Department of Atmospheric Sciences, University of Hawaii at Manoa, Honolulu, HI 96822, USA \\ ${ }^{5}$ NOAA/Geophysical Fluid Dynamics Laboratory, Princeton, NJ 08540, \\ and University Corporation for Atmospheric Research, Boulder, CO 80307, USA
}

(Received 17 September 2014; revised 10 December 2014; accepted 10 December 2014)

\begin{abstract}
A coupled earth system model (ESM) has been developed at the Nanjing University of Information Science and Technology (NUIST) by using version 5.3 of the European Centre Hamburg Model (ECHAM), version 3.4 of the Nucleus for European Modelling of the Ocean (NEMO), and version 4.1 of the Los Alamos sea ice model (CICE). The model is referred to as NUIST ESM1 (NESM1). Comprehensive and quantitative metrics are used to assess the model's major modes of climate variability most relevant to subseasonal-to-interannual climate prediction. The model's assessment is placed in a multi-model framework. The model yields a realistic annual mean and annual cycle of equatorial SST, and a reasonably realistic precipitation climatology, but has difficulty in capturing the spring-fall asymmetry and monsoon precipitation domains. The ENSO mode is reproduced well with respect to its spatial structure, power spectrum, phase locking to the annual cycle, and spatial structures of the central Pacific (CP)-ENSO and eastern Pacific (EP)-ENSO; however, the equatorial SST variability, biennial component of ENSO, and the amplitude of CP-ENSO are overestimated. The model captures realistic intraseasonal variability patterns, the vertical-zonal structures of the first two leading predictable modes of Madden-Julian Oscillation (MJO), and its eastward propagation; but the simulated MJO speed is significantly slower than observed. Compared with the T42 version, the high resolution version (T159) demonstrates improved simulation with respect to the climatology, interannual variance, monsoon-ENSO lead-lag correlation, spatial structures of the leading mode of the Asian-Australian monsoon rainfall variability, and the eastward propagation of the MJO.
\end{abstract}

Key words: coupled climate model, earth system model, climate variability

Citation: Cao, J., and Coauthors, 2015: Major modes of short-term climate variability in the newly developed NUIST Earth System Model (NESM). Adv. Atmos. Sci., 32(5), 585-600, doi: 10.1007/s00376-014-4200-6.

\section{Introduction}

Since the pioneering work of Manabe and Bryan (1969), immense progress has been made in the development of coupled global climate models (CGCMs) and earth system models (ESMs). Such model development has been continuously inspired by tremendous scientific and societal demands in dynamical climate prediction and future projection of the response of the climate system and earth system to anthropogenic forcing.

On the climate prediction front, simulation and prediction

\footnotetext{
* Corresponding author: Baoqiang XIANG

Email: baoqiang.xiang@noaa.gov
}

of ENSO was a primary endeavor in the 1980s and 1990s, starting from the ground-breaking work of ENSO prediction with a coupled model of intermediate complexity (Cane et al., 1986; Zebiak and Cane, 1987) to numerical modeling and prediction of ENSO using CGCMs (Mechoso et al., 1995; Latif et al., 2001; Davey et al., 2002). Accordingly, the dynamical prediction of global climate anomalies emerged using atmospheric global climate models (AGCMs) forced by forecasted SST as boundary forcing, i.e., the two-tier approach (Bengtsson et al., 1993). It was later found that monsoon variability is not only a response to ENSO, but also strongly involves local atmosphere-ocean interaction (Wang et al., 2000; Lau and Nath, 2000). Thus, even using the strongest observed SST anomalies associated with the un- 
precedented 1997-98 ENSO event, an AGCM alone failed in simulating the Asian monsoon precipitation anomalies due to neglecting the atmospheric feedback to the ocean (Wang et al., 2005). The results of multi-model hindcast experiments indicate that monsoon prediction requires a coupled model and one-tier approach for seasonal prediction (Wang et al., 2004, 2005). Today's climate prediction models include atmosphere, ocean, land, and sea ice components and their interactive processes.

On the future projection front, stimulated by the first Global Change Symposium in 1984, the International Geosphere-Biosphere Programme was established in 1986 by the International Council of Scientific Unions. The need to study global change propelled the modeling community to couple the physical climate system with biogeochemical processes and human influence, transforming the focus from climate system models (CSMs) to ESMs. The ESM aims to predict global environmental changes involving interactions between the atmosphere, hydrosphere, lithosphere, cryosphere, biosphere and anthroposphere (i.e. human activity). Starting from the beginning of the 21st century, the ESM provides an effective tool for comprehensively studying the earth system.

In recent decades, Chinese atmospheric and oceanic communities have been making great efforts to develop CSMs and ESMs to meet the demands of climate prediction and future projection in China. The first CSM built in China was the Flexible Global Ocean-Atmosphere-Land System gird version 1.0 (FGOALS-g1.0) model by the Institute of Atmospheric Physics (IAP), Chinese Academy of Sciences (CAS) (Yu et al., 2008). Another CSM was built at the Beijing Climate Center (BCC-CM1) (Ding et al., 2000). The performance of both FGOALS-g1.0 and BCC-CM1 was comprehensively evaluated in the Coupled Model Intercomparison Project Phase 3 (CMIP3). After CMIP3, modeling groups in China made great efforts to improve their CSMs, including increasing model resolution, improving physical parameterization, and implementing more component models and upgrading to ESMs. For example, the ESM of Beijing Normal University (BNU-ESM) (Ji et al., 2014) and that of the First Institute of Oceanography (FIO-ESM) (Qiao et al., 2013) were developed based on the structure of version 4 of the Community Climate System Model (CCSM4). BNU-ESM is characterized by its land surface model, the Common Land Model (Dai et al., 2003, 2004), and FIO-ESM made a first attempt to incorporate a surface wave model into its structure (Qiao et al., 2013). These four model groups participated in CMIP5. Alongside these developments, a new coupler, the Community coupler (C-coupler), has been developed at Tsinghua University (Liu et al., 2014).

Recently, a coupled ESM has been developed at Nanjing University of Information Science and Technology (NUIST), referred to as NESM. The objectives in developing NESM are to meet the multiple needs for seamless climate prediction, projecting future global environment changes, and modeling paleoclimate changes and high-impact climate events. The strategy for the development of NESM was initially, as a first step, to take full advantage of existing world-class compo- nent models and to focus on the coupled physics. This will then be followed by continual improvement of the component models and the addition of more components through close collaboration with other modeling groups. A special endeavor of the NESM project is to realistically simulate the major climate processes that are unique to the Asia-Pacific region, such as monsoon and ENSO. In developing the model, it is hoped that application can be achieved in subseasonal-todecadal forecasting at national meteorological and oceanographic operational centers. Furthermore, another target for the model is to participate and contribute as much as possible to international modeling projects, such as the subseasonalto-seasonal (S2S) project and the forthcoming World Climate Research Program/Coupled Model Intercomparison Project Phase 6 (CMIP6).

In the present paper, we briefly introduce (in section 2) the basic features of the first version of NESM, i.e. NESM1. Our major aim at this point in the model's development is to assess its capacity in simulating short-term climate variability. The evaluation strategy, metrics and methods used to achieve this are described in section 3, followed by a presentation of the model evaluation results in section 4 . The assessment focuses on the model's capability in simulating the primary modes of climatology and S2S variability. A more comprehensive evaluation of the simulation of land surface, sea ice, and oceanic processes and variability, as well as teleconnection patterns, will be reported in future work.

\section{Development of NESM1}

NESM1 consists of three component models: version 5.3 of the Max Planck Institute's ECHAM atmospheric mode, version 3.4 of the Nucleus for European Modelling of the Ocean (NEMO), and version 4.1 of the Los Alamos sea ice model (CICE). The three component models are coupled via a fully parallelized coupler: version 3.0 of the OceanAtmosphere-Sea-Ice-Soil (OASIS, v3.0) Model Coupling Toolkit (OASIS3-MCT). The land surface model is included in the ECHAM component. Each component of the coupled system is briefly described in the following subsections.

\subsection{The ECHAM (v5.3) atmospheric model}

The ECHAM atmospheric general circulation model is introduced in detail in Roeckner et al. (2003). However, a brief description is also summarized here. ECHAM v5.3 employs a spectral dynamical core with a triangular truncation of spherical harmonics and a semi-implicit leapfrog time difference scheme. A flux-form semi-Lagrangian scheme is used for the passive tracer (all water components and chemical substances). The shortwave radiation scheme uses the Eddington approximation for the integration over the zenith and azimuth angles and the delta-Eddington approximation for the reflectivity of a layer (Fouquart and Bonnel, 1980). The longwave radiation scheme uses the Rapid Radiative Transfer Model (RRTM) (Mlawer et al., 1997). A mass flux parameterization scheme for cumulus convection (Tiedtke, 
1989) is used for shallow, mid-level and deep convection. The stratiform cloud scheme contains a cloud microphysical scheme (Lohmann and Roeckner, 1996) with separate prognostic equations for the vapor, liquid, and ice phases. The land surface is coupled with the atmosphere via an implicit scheme in ECHAM v5.3.

\subsection{The NEMO (v3.4) ocean model}

NEMO v3.4 is a framework of ocean related models, including OPA (Ocean PArallelise) for the ocean dynamics and thermodynamics, LIM (Louvain-la-Neuve Sea Ice Model) for the sea-ice dynamics and thermodynamics, TOP (Tracer in the Ocean Paradigm) for the biogeochemistry and sourcesminus-sinks of carbon (Madec and NEMO team, 2012). It is an ocean model originally based on OPA8.2 and developed under the NEMO framework. NESM1 uses the NEMO ocean part (OPA).

The primitive equations for the ocean model are written in a curvilinear coordinate system, with a z-coordinate partial step formulation (Barnier et al., 2006). The model is discretized on a staggered grid (Arakawa $\mathrm{C}$ grid) with masking of land areas. In the momentum equation, the total energy and potential enstrophy are conserved in the limit of horizontally nondivergent flow (Le Sommer et al., 2009). The Total Variance Dissipation (TVD) scheme (Zalesak, 1979) is used to calculate the advection of tracers. The mixed layer dynamics is parameterized using the Turbulent Kinetic Energy (TKE) closure scheme (Madec et al., 1998). Double diffusion mixing is adopted with a heat-salt buoyancy flux ratio of 1.6 and a maximum vertical mixing of salinity of $1 \times 10^{-4} \mathrm{~m}^{2} \mathrm{~s}^{-1}$. The incoming solar radiation is distributed in the surface layers of the ocean using penetration parameters (Lengaigne et al., 2009).

\subsection{The CICE (v4.1) sea ice model}

The NEMO ocean model has the CICE (Hunke and Lipscomb, 2010) model as a module, which employs a zerolayer thermodynamic model with one layer of ice and one layer of snow in the vertical direction. Ice surface temperature, atmosphere-to-ice fluxes, and the conductive heat flux through the ice to the ocean have to be calculated in the atmospheric component. This has been used by EC-Earth (Hazeleger et al., 2010) and HadGEM3 (Hewitt et al., 2011). In NESM1, the CICE module is not used in NEMO, but is instead treated as a component model, and the multi-layer thermodynamic scheme is employed with four vertical ice layers and one snow layer. This is more efficient in that the CICE model can determine the net ice characteristics of the grid cell and provide the exchanging fluxes.

NESM1 employs the CICE v4.1 tripolar grid configuration with the Elastic-Viscous-Plastic (EVP) scheme for internal ice stress. The delta-Eddington radiative scheme is used for computing the albedo and shortwave fluxes. The subgridscale ice thickness distribution (ITD) divides the ice pack into five ice categories and an open water category, which have different thicknesses, different surface properties, and different melt and growth rates, as computed by the thermodynam- ics. The lower bounds of ice thickness used in NESM1 are 0 , $0.6,1.4,2.4$ and $3.6 \mathrm{~m}$. The layered thermodynamic scheme is used to determine the changes of thickness and the vertical temperature profile in each category.

\subsection{The OASIS3-MCT coupler}

The OASIS3-MCT interfaced with MCT (Larson et al., 2005) is used to synchronize, interpolate and exchange the coupling fields among the atmospheric, oceanic and seaice component models. In NESM1, all interpolation coefficients are pre-computed based on re-gridding weights and addressed by using the Spherical Coordinate Remapping and Interpolation Package (SCRIP) library, which is included in OASIS3-MCT. As a parallel coupler, it implements a fully parallel re-gridding (as a parallel matrix vector multiplication) and parallel distributed exchanges of the coupling fields. All model processes are involved to transfer information over the coupler subdomains, and parallel file inputs/outputs are also supported.

\subsection{The coupling strategy and methodology}

To avoid climate drift in the coupled system, heat and freshwater flux conservation interpolation are applied to keep the global energy balance (e.g., Hewitt et al., 2011; Xiang et al., 2012). There are 36 variables in total to be exchanged among the three model components, and the coupling frequency is once per day, which is managed by the OASIS3MCT coupler.

For the ocean-atmosphere coupling, the ECHAM atmospheric model drives the ocean model with surface wind stress, heat and freshwater fluxes, while the NEMO ocean model sends SST and ocean surface currents back to the atmospheric model. In the ocean-ice coupling system, NEMO receives information on the ice fraction, ocean-ice stress, melting freshwater flux, salt flux, net ocean-ice heat flux, and penetrative shortwave radiation through ice to the ocean, and provides information on the SST, sea surface salinity (SSS), surface currents, sea surface slope, and ice freezing/melting flux to the CICE model. Finally, for the atmosphere-ice coupling, CICE provides information on the ice fraction, ice surface temperature, and ice surface albedo to ECHAM. Meanwhile, ECHAM sends information on the atmospheric level height, zonal and meridional winds, specific humidity, air density, air potential temperature, air temperature, downward shortwave and longwave radiation, and rainfall and snowfall fluxes to the CICE model.

Note that the heat fluxes between the ocean and atmosphere are calculated in ECHAM, while several other fluxes are calculated in CICE (e.g., latent and sensible heat fluxes) for the atmosphere-ice coupling. The reason is twofold. First, some of the fluxes depend strongly on the state of the ice, indicating that an implicit, simultaneous determination of the ice state and surface fluxes is necessary for consistency and stability. Second, due to various ice types coexisting in a single grid cell, it is more efficient for the ice model to determine the net ice characteristics of a grid cell and provide the corresponding fluxes to the other model components. 


\subsection{Experimental design}

Two versions of NESM1 were used in this study. In NESM1 (T42), the atmospheric component resolution is T42L31, which corresponds to a horizontal resolution of about $2.8^{\circ}$ and 31 vertical layers extending from the surface to $10 \mathrm{hPa}$. The horizontal resolution for the ocean model is about $2^{\circ} \times 2^{\circ}$ over the extratropical region and about $2^{\circ}$ (lon) $\times 0.5^{\circ}$ (lat) over the tropical region. It has 31 layers with a 10 $\mathrm{m}$ resolution for the upper 10 layers. The horizontal resolution for the sea ice model is about $1^{\circ}$ (lon) $\times 0.5^{\circ}$ (lat) with four ice layers and one snow layer. NESM1 (T159) has the same configuration as NESM1 (T42), except that the atmospheric model horizontal resolution is $\mathrm{T} 159$ (about $0.75^{\circ}$ ). In order to evaluate the forced response and internal feedback of the two versions of NESM1, two sets of experiments were conducted with the external forcing (greenhouse gases, solar constant etc.) fixed at the level of the year 1990. A 100-year free coupled run was performed after a 300-year spin up with NESM1 (T42). In the NESM1 (T159) simulation, we used the same ocean and sea-ice model and their configurations as for NESM1 (T42). An additional 30-year simulation was carried out after a further 10-year spin up using the ocean and sea-ice initial conditions from NESM1 (T42). The study used the $\mathrm{T} 42$ results, except for precipitation simulation, where the T159 results were used. Unless specific mention is made of T159, NESM1 in this paper is an abbreviation of NESM1 (T42).

\section{Evaluation strategy, metrics and methods}

Continuing improvement of ESMs requires systematic evaluation and tracking of models' performances. Two types of fundamental processes need to be diagnosed: (1) the forced response of the climate system to external forcing, such as solar radiation, which is primarily reflected in the annual cycle; and (2) internal feedback processes within the atmosphere or the coupled climate system, such as MaddenJulian Oscillation (MJO), ENSO, and other modes of climate variability.

Given that societal needs for prediction from weekly to seasonal time scales are great (Vitart et al., 2012), our evaluation of NESM1 is primarily aimed at S2S prediction. More specifically, we focus on the climatology, ENSO, monsoon variability, and intraseasonal oscillation (ISO). The major variables examined are precipitation, a key element of the hydrological cycle and atmospheric dynamics, SST, and surface circulation, which are important indicators of the atmosphere-ocean coupling.

The observational data used to validate the simulations include: (1) Global Precipitation Climatology Project (GPCP), version 2.2 (Huffman et al., 2009); (2) the improved Extended Reconstructed Sea Surface Temperature (SST) dataset, version 2 (ERSST V2) (Smith and Reynolds, 2004); (3) the atmospheric fields from the National Centers for Environmental Prediction (NCEP)/Department of Energy (DOE) Reanalysis II (Kanamitsu et al., 2002); (4) wind stress from the NCEP Real-time Marine (http://esrl.noaa.gov/psd/) dataset; and (5) gridded daily outgoing longwave radiation (OLR) (Liebmann and Smith, 1996) from the National Center for Atmospheric Research (NCAR). For comparison, we also use University of Hawaii POEM2 model results (Xiang et al., in preparation) and historical simulations of 20 CGCMs that participated in CMIP5. The pattern correlation coefficient (PCC) and normalized root-mean-square error (NRMSE), often used as validation measures for simulated two-dimensional fields (Wang et al., 2009), are employed. The threat score is used to measure the simulation skill in the monsoon domain, which is defined by the number of "hit" grids divided by the sum of "hit", "missed", and "false-alarm" grids (Wang et al., 2011).

The mean climatology in coupled models is recognized as critical for realistic simulation of the ISO, monsoon variability, and ENSO-monsoon teleconnection (Turner et al., 2005; Lee et al., 2010; Waliser, 2011). We evaluate SST climatology in terms of (1) the long-term mean (figure not shown) and (2) the annual cycle of the equatorial Pacific SST and associated zonal wind stress. The annual mean SST is crucial for realistic simulation of tropical precipitation and circulation. The annual cycle of the equatorial SST is vital for testing the model's capability in capturing the equatorial atmosphereocean interaction and the simulation of ENSO's amplitude and phase locking (Mitchell and Wallace, 1992; Nigam and Chao, 1995). The diagnostic metrics for evaluation of the climatology of precipitation follow the approach proposed by Wang et al. (2011), which includes (1) the annual mean, (2) the solstice and equinoctial asymmetric modes of the annual cycle, and (3) the global monsoon (GM) precipitation intensity and domain. The performance in the GM precipitation domain reflects the model's capability in simulating the seasonal distribution of precipitation, as well as the total amount of annual precipitation at each location.

The ENSO is of central importance for determining tropical and global teleconnection, and thus it is a major source of global climate predictability on seasonal to interannual time scales. Our ENSO evaluation metrics consist of (1) the monthly mean SST variance pattern, (2) the spatial structure of the dominant empirical orthogonal function (EOF) mode of the Pacific SST during the Northern Hemisphere winter, (3) the phase lock of ENSO evolution to the annual cycle, (4) the power spectrum of Niño3 index, and (5) the spatiotemporal structure of the two types of ENSO, i.e., the Eastern Pacific (EP)- and Central Pacific (CP)-ENSO.

The importance of the monsoon variability can never be over-emphasized, as it affects the daily lives of two thirds of the world's population. In contrast to ENSO prediction, the simulation and seasonal prediction of Asian-Australian monsoon (AAM) rainfall variability have long been a great challenge (Sperber and Palmer, 1996; Gadgil and Sajani, 1998; Goswami, 1998; Wang et al., 2008b; Wang et al., 2014). The difficulty in simulating and predicting the Asian summer monsoon's seasonal rainfall is in part due to limitations in predicting the monsoon's intrinsic internal variability. The performance in simulating the variation of the GM and 
its strongest component, the AAM system, is evaluated in terms of the (1) interannual variability of seasonal mean precipitation, (2) leading mode of season reliant-EOF (S-EOF) analysis of the seasonal mean precipitation anomalies over the AAM region $\left(30^{\circ} \mathrm{S}-40^{\circ} \mathrm{N}, 60^{\circ}-160^{\circ} \mathrm{E}\right)$, and (3) ENSOmonsoon lead-lag relationships. The purpose of S-EOF is to depict seasonally evolving anomalies throughout a full calendar year. The methodology is detailed in Wang and An (2005)

The MJO interacts with, and influences, a wide range of weather and climate phenomena (e.g., monsoons, ENSO, tropical storms, midlatitude weather), and represents an important source of predictability at the subseasonal time scale (Zhang et al., 2013). Thus, it is important for climate models to reproduce the intrinsic mode of the ISO realistically in their free-coupled runs. Evaluation of the ISO follows the MJO simulation diagnostics designed by the US CLIVAR MJO working group (Waliser et al., 2009), which include (1) the intraseasonal variance, (2) the wavenumber-frequency spectrum, and (3) the spatiotemporal structure of the first two leading modes.

\section{Simulated major modes of climate variabil- ity in NESM1}

\subsection{Climatological mean and annual cycle}

A realistic simulation of tropical mean SST acts as a precondition for realistic ENSO simulation (e.g., Xiang et al., 2012). NESM1 simulates the observed annual mean SST very well $(\mathrm{PCC}=0.95)$ (Table 1$)$, especially the Indo-Pacific warm pool and the eastern Pacific cold tongue (figure not shown). However, a warm bias in excess of $2^{\circ} \mathrm{C}$ appears off the western coasts of America and Africa, which is likely linked to errors in simulating stratus clouds, oceanic upwelling and marine boundary air-sea feedbacks. Meanwhile, a considerable cold SST bias is found in part of the North Pacific (about $-2^{\circ} \mathrm{C}$ ).

The annual cycle of equatorial Pacific SST is simulated reasonably realistically $(\mathrm{PCC}=0.86)$ (Fig. 1). However, compared to observations, the maximum warming is shifted by about $20^{\circ}$ of longitude westward and the timing of the maximum warming in the EP is delayed by about 1 month. NSEM1 only captures the large-scale features of the annual cycle of the equatorial zonal wind stress $(\mathrm{PCC}=0.54)$, and the amplitude is too strong. The largest errors occur from January to March, which may affect ENSO evolution. The wind stress variability over the western Pacific is excessively strong, reflecting the deficiency in simulating the Australian monsoon, which may affect the simulated ISO in the western Pacific.

Precipitation simulations and forecasts remain one of the most challenging issues in current coupled models. For the CGCMs that participated in CMIP3, only 6 out of 18 models were found to have relatively realistic monsoon climatology (Annamalai et al., 2007). Figure 2a shows that NESM1 (T159) reproduces the overall features reasonably well

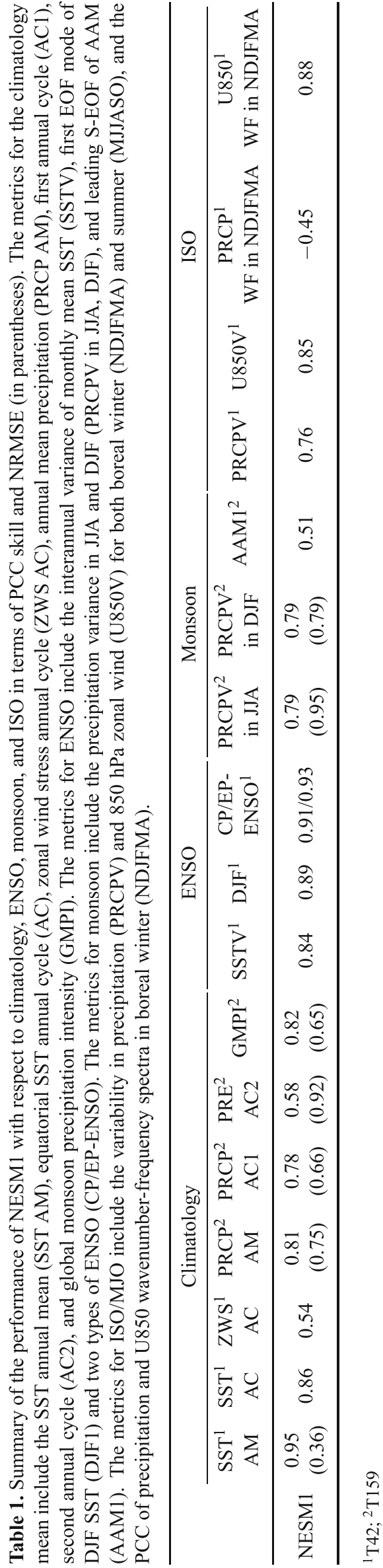


(a) SSTA

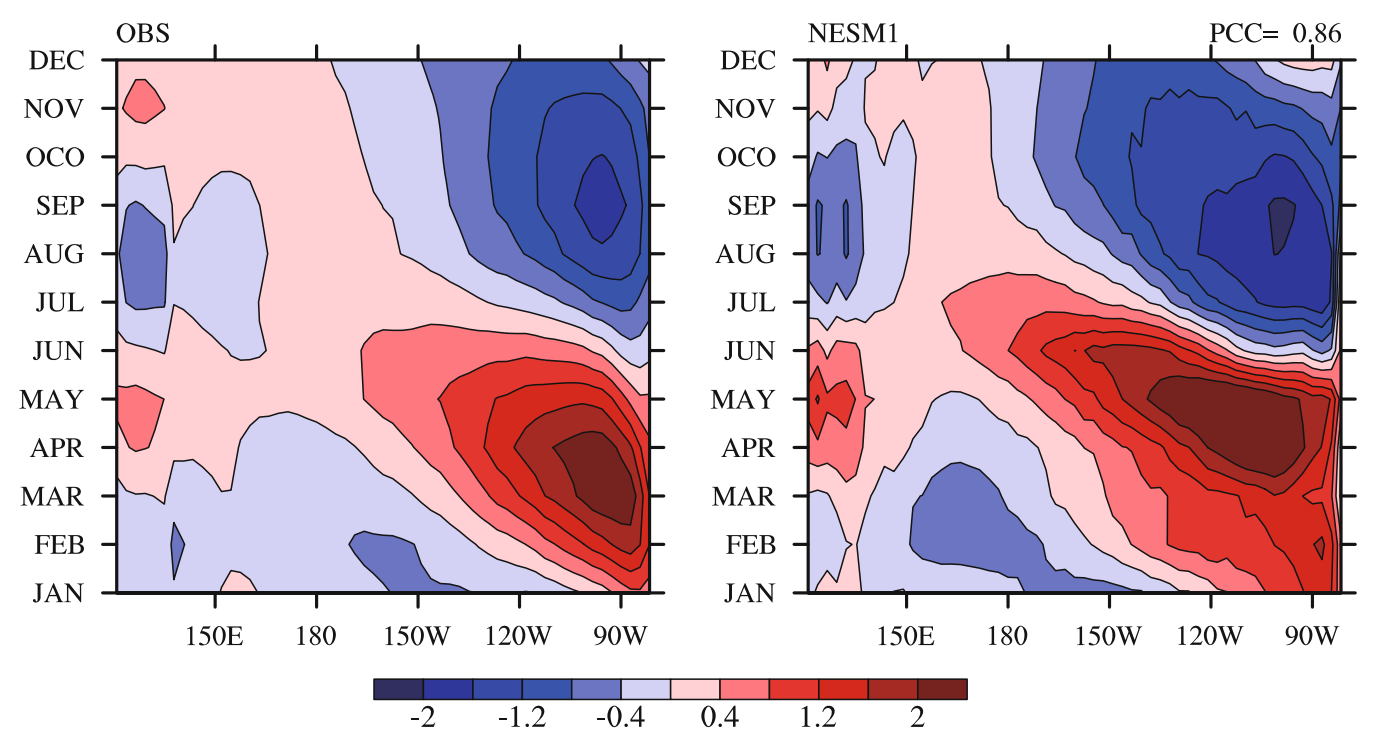

(b) Zonal wind stress
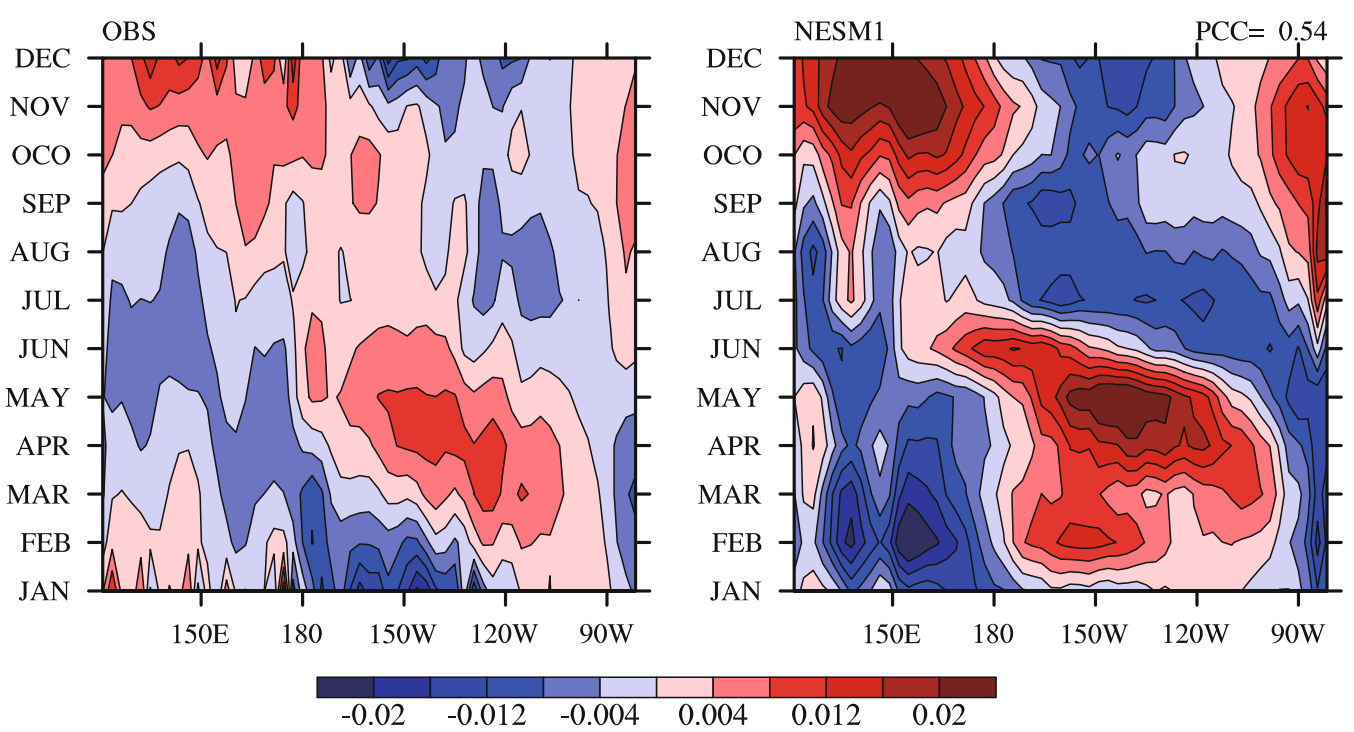

Fig. 1. Annual cycle of (a) SST anomalies (deviation from the climatological mean) (units: ${ }^{\circ} \mathrm{C}$ ) and (b) zonal wind stress (unit: $\mathrm{N} \mathrm{m}^{-2}$ ) from observation (left) and NESM1 (T42) (right) averaged over the Pacific equatorial region $\left(5^{\circ} \mathrm{S}-5^{\circ} \mathrm{N}\right)$. ERSST v2 and NECP Real-time Marine wind stress data are used for comparison as the observations. The pattern correlation coefficient (PCC) between observed and simulated patterns is indicated in the top-right corner of the bottom panels.

$(\mathrm{PCC}=0.78)$, especially the major oceanic convergence zones over the tropics: the intertropical convergence zone (ITCZ), the South Pacific convergence zone (SPCZ), and the equatorial South Indian Ocean (IO) convergence zone. However, excessive precipitation presents over the north and south of the equatorial regions (the so-called double ITCZ problem). The model produces the major precipitation zones in the extratropical Pacific and Atlantic realistically, which are associated with oceanic storm tracks. One salient feature is that the precipitation is overestimated in the majority of ocean basins, which may be related to the warm SST bias in the tropical oceans and the intrinsic atmospheric model's excessive convergence in the ITCZ.

Wang and Ding (2008) defined two annual cycle modes of precipitation according to EOF analysis of the climatological monthly mean precipitation. The first EOF mode, representing a solstice global monsoon mode, can be well represented by the difference between June-July-AugustSeptember (JJAS) and December-January-February-March (DJFM) mean precipitation. The second EOF mode, representing an equinox asymmetric mode, can be explained by the difference between April-May (AM) and October- 
(a) Annual mean precipitation ( $\mathrm{mm} /$ day)

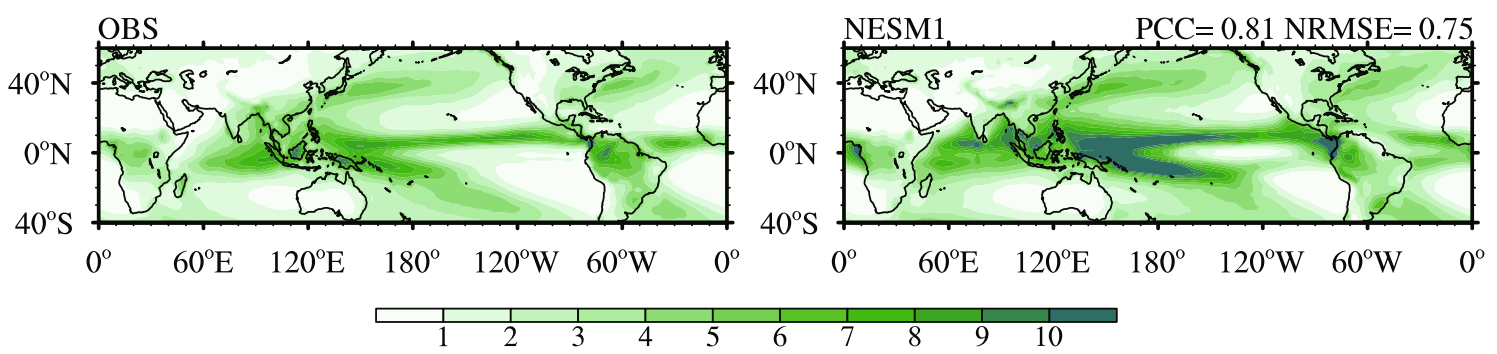

(b) The first annual cycle (mm/day)

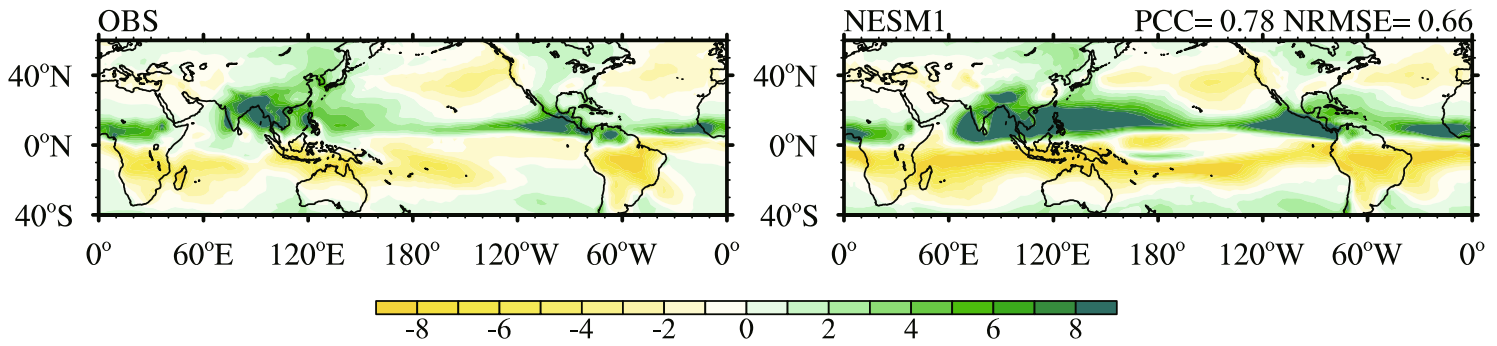

(c) The second annual cycle (mm/day)

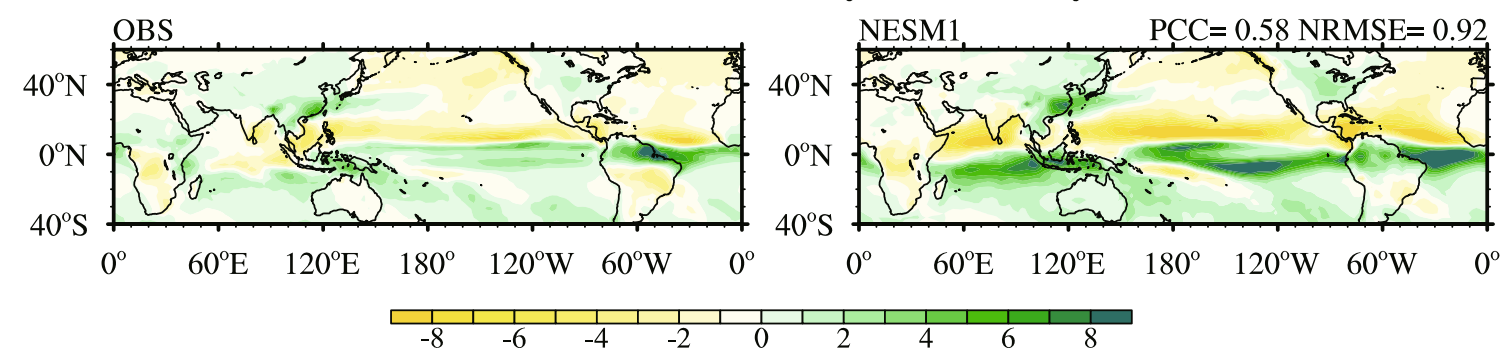

Fig. 2. The observed (GPCP v2.2) (left) and simulated (right) (a) annual mean, (b) first annual cycle (solstice mode, JJAS minus DJFM), and (c) second annual cycle (equinoctial asymmetric mode, AM minus ON) of precipitation (units: $\mathrm{mm} \mathrm{d}^{-1}$ ). The simulated precipitation data are from NESM1 (T159). The pattern correlation coefficient (PCC) between observed and simulated patterns, and the domain-averaged $\left(40^{\circ} \mathrm{S}-60^{\circ} \mathrm{N}, 0^{\circ}-360^{\circ}\right)$ RMSE normalized by the observed spatial standard deviation (NRMSE), are indicated in the top-right corner of the bottom panels.

November (ON) mean precipitation. The two leading annualcycle modes of precipitation account for $68 \%$ and $15 \%$ of the total observed annual variation of precipitation, respectively. Figure $2 \mathrm{~b}$ indicates that the model reproduces the observed first annual cycle (solstice) mode realistically with little bias, but has difficulty in capturing the second annual cycle (equinox) mode (Fig. 2c). It tends to overestimate the solstice monsoon mode over the western Pacific monsoon region, and also overestimates the equinox asymmetric mode over the Southern Hemisphere tropics.

The observed and simulated GM precipitation intensity and monsoon domains are shown in Fig. 3. The GM precipitation intensity is defined by the ratio of local summerminus-winter mean precipitation over the annual mean precipitation and the GM precipitation domain is defined by the regions where the summer-minus-winter precipitation exceeds $2.5 \mathrm{~mm} \mathrm{~d}^{-1}$ and the GM precipitation intensity exceeds 0.55 (Wang and Ding, 2008; Lee and Wang, 2014). NESM1 (T159) reproduces the GM precipitation intensity reasonably well with a $\mathrm{PCC}$ of 0.82 , but underestimates the intensity over the East Asian monsoon regions and overestimates the intensity over the tropical oceans. The simulated monsoon domains are less impressive, with a threat score of 0.52, but comparable with current CMIP5 models (Lee and Wang, 2014).

\subsection{ENSO simulation}

NESM1 simulates the interannual variance of monthly mean SST reasonably well $(\mathrm{PCC}=0.84)$ (Table 1$)$, but the amplitude is significantly larger than observed, with a significant westward shift of the variance center (figure not shown). The PCC skill for the spatial distribution of the first EOF mode of the averaged DJF tropical Pacific SST anomalies (Fig. 4) is high (0.89). In order to compare the performance of NESM1 in simulating ENSO with other CGCMs, the performance of NESM1, POEM2 and 20 CMIP5 CGCMs in capturing the spatial distribution of monthly variance and the first EOF mode of the tropical Pacific SST anomalies during 
(a) OBS

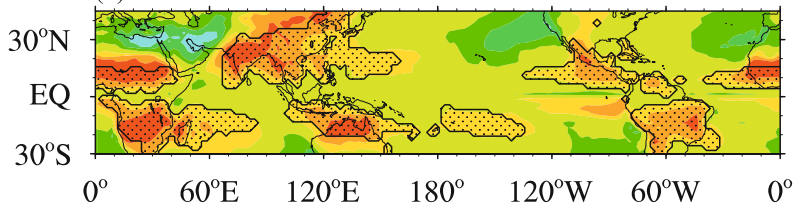

(b) NESM1 $\quad \mathrm{PCC}=0.82 \quad \mathrm{NRMSE}=0.65 \quad$ TS core $=0.52$

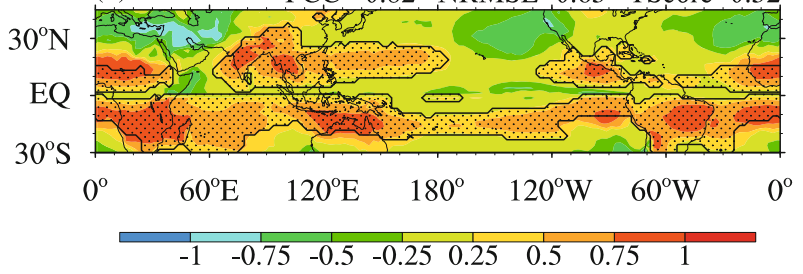

Fig. 3. The global monsoon precipitation intensity (shading) and domain (outlined by black lines and dotted) in (a) observation and (b) NESM1 (T159). The PCC between observed and simulated patterns, the domain-averaged $\left(30^{\circ} \mathrm{S}-45^{\circ} \mathrm{N}, 0^{\circ}-\right.$ $360^{\circ}$ ) RMSE normalized by the observed spatial standard deviation (NRMSE), and the threat score are indicated in the topright corner of (b).

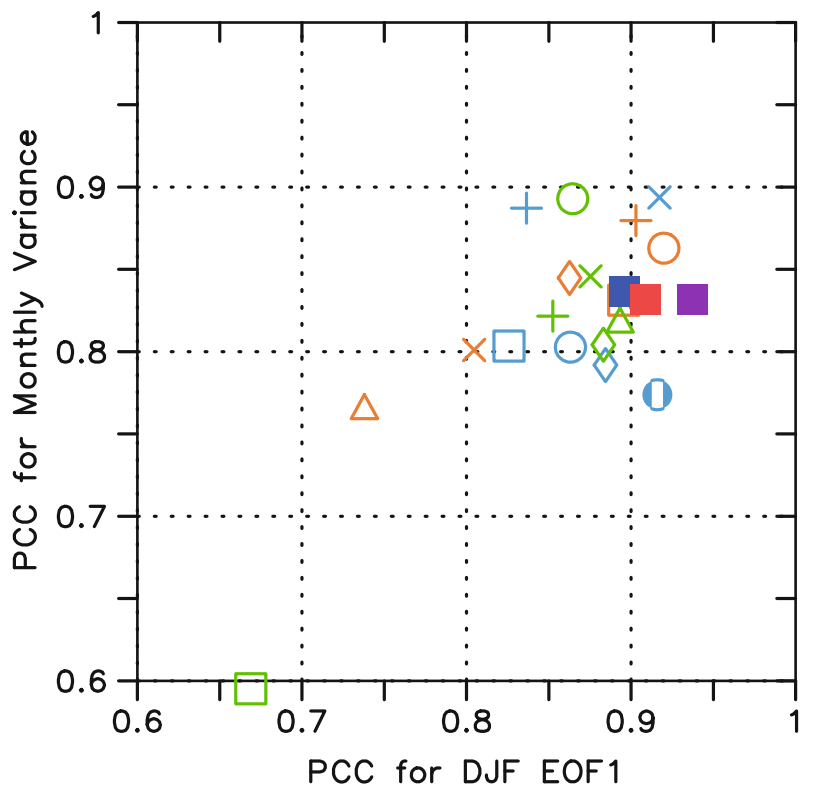

DJF are summarized in Fig. 4. It is noted that NESM1 is among the top models with respect to the spatial distribution of monthly variance and the dominant mode of DJF ENSO variability.

ENSO phase locking to the seasonal cycle can be seen clearly using the standard deviation (STD) of Niño3 index for each calendar month (An and Wang, 2001). NESM1 shows similar results to those based on observations, which is characterized by a maximum peak in November-January (Fig. $5 a)$, although the seasonal variation in NESM1 is weaker.

(a) Monthly Nino3 STD

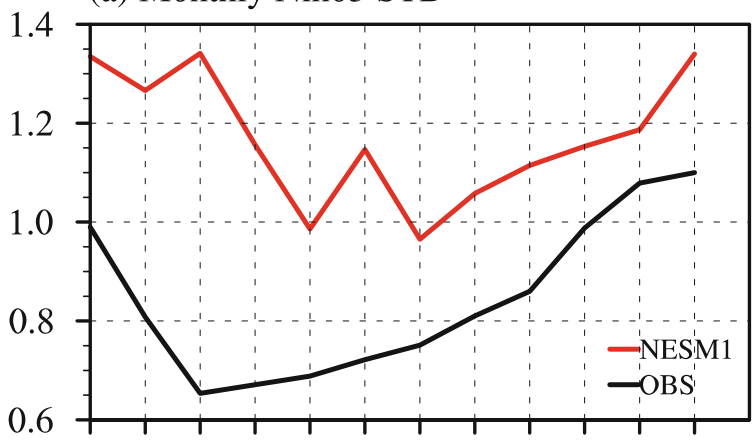

Jan FebMarAprMayJun Jul AugSep Oct NovDec

(b) OBS

Nino3 Power Spectra

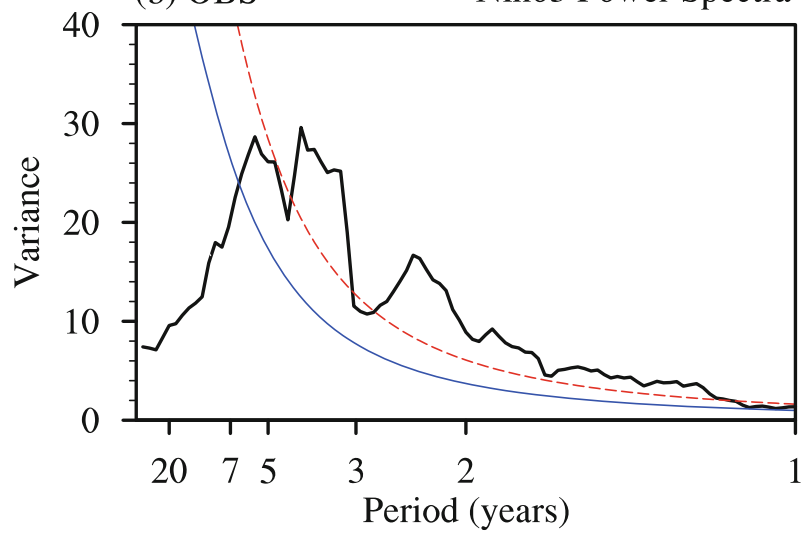

(c) NESM1

Nino3 Power Spectra

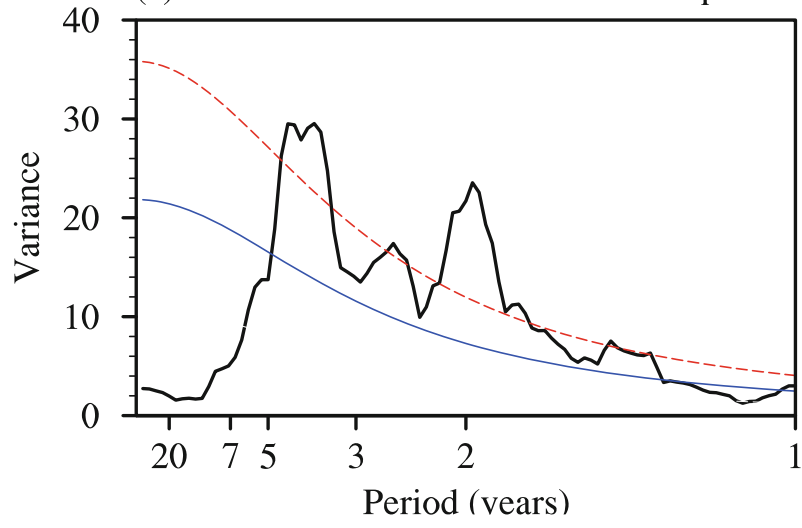

Fig. 5. (a) Monthly standard deviation (STD) of Niño3 SST anomalies, and power spectra of Niño3 SST anomaly in (b) observation and (c) NESM1. The red and black solid lines in (a) are from ERSST and NESM1, respectively. In (b) and (c), the blue lines indicate red noise, and the red dashed lines indicate the $95 \%$ confidence level.

Fig. 4. Performance of NESM1, POEM 2 and 20 CMIP5 CGCMs in capturing the spatial distribution of the first EOF mode of the averaged DJF tropical Pacific SST anomalies (abscissa) and the monthly mean variance (ordinate) in terms of the PCC skill. The tropical Pacific is the region $\left(20^{\circ} \mathrm{S}-20^{\circ} \mathrm{N}\right.$, $\left.100^{\circ} \mathrm{E}-80^{\circ} \mathrm{W}\right)$. 
Moreover, the minimum Niño3 standard deviation in NESM1 is delayed by about 2 months with respect to observations. The major observed peak of ENSO variability (Niño3 index) is about 2-7 years (Fig 5b). NESM1 simulates the frequency of the Niño3 SST anomaly well, with major peaks at 2 years and $4-5$ years (Fig. $5 c$ ).

Recent studies have identified two types of El Niño: CPEl Niño and the traditional EP-El Niño, and their global climate impacts are distinctly different (Ashok et al., 2007; Yeh et al., 2009; Kim et al., 2009; Ding et al., 2011). More frequent occurrence of CP-El Niño in recent decades can be attributed to greenhouse gas forcing (Yeh et al., 2009) as well as natural decadal variability (Ashok et al., 2007; Xiang et al., 2013). It is interesting to examine the different types of ENSO in climate models because it is important to predict their different climate impacts and project their future changes.

As discussed in Kao and Yu (2009), a combined regression-EOF analysis is used to identify the two types of ENSO. The spatial patterns of leading EOF modes for CP- and EP-ENSO obtained over the domain $\left(20^{\circ} \mathrm{S}-20^{\circ} \mathrm{N}\right.$, $120^{\circ} \mathrm{E}-80^{\circ} \mathrm{W}$ ) from observations and from NESM1 are illustrated in Fig. 6. The loading coefficients for EOFs are scaled by the square root of their corresponding eigenvalues to represent the STD of each EOF mode. The CP-ENSO is characterized by SST variability centered in the central tropical Pacific, and the EP-ENSO features SST variability extending from the South American coast into the central Pacific along the equator. NESM1 successfully reproduces the observed spatial structures of CP- and EP-ENSO $(\mathrm{PCC}=0.91$ and 0.93 , respectively). The observed and simulated explained variances for CP-ENSO are $41.0 \%$ and $28.4 \%$, respectively, while for EP-ENSO they are $40.7 \%$ and $17.0 \%$. The maximum STDs are used to quantify the intensities of the two types of ENSO. It is noted that the observed intensity of CPENSO is close to $70 \%$ of the EP-ENSO intensity. However, in NESM1, the CP- and EP-ENSOs have comparable amplitudes, indicating that NESM1 overestimates the intensity of CP-ENSO.

\subsection{Monsoon rainfall variability}

To evaluate NESM1's capability in capturing the AAM variability, we examine how NESM1 (T159) simulates the first S-EOF mode of the AAM precipitation variability. Figure $7 \mathrm{a}$ presents the spatial patterns of the leading S-EOF modes of AAM precipitation. The model reasonably reproduces the spatial structure of the leading S-EOF mode of the AAM rainfall variability. However, NESM1 (T159) underestimates the rainfall variability over the equatorial western Pacific and Maritime Continent. This is partially associated with the westward shift of the ENSO SST anomalies. Another bias is found during SON and DJF, when the model exhibits enhanced precipitation over the western tropical Indian Ocean, in strong contrast to the observed smaller precipitation anomalies. This bias may have some impacts on Indian Ocean Dipole (IOD) simulation, given the tight relationship between ENSO and IOD (e.g., Saji and Yamagata, 2003). In summary, the model is able to capture the leading S-EOF mode of the AAM rainfall variability in terms of its association with ENSO, but demonstrates some errors in the simulated spatial patterns, especially during the developing phase of ENSO. It is also worth noting that the monsoonENSO relationship, i.e., the first mode associated with ENSO turnaround (Wang et al., 2008a), is realistically captured by the model, as demonstrated in Fig. 7b.

Figure 8 shows the performance of NESM1 in simulating the variance of JJA precipitation in terms of the PCC skill and season-averaged PCC skill for the first S-EOF mode (a) CP-ENSO

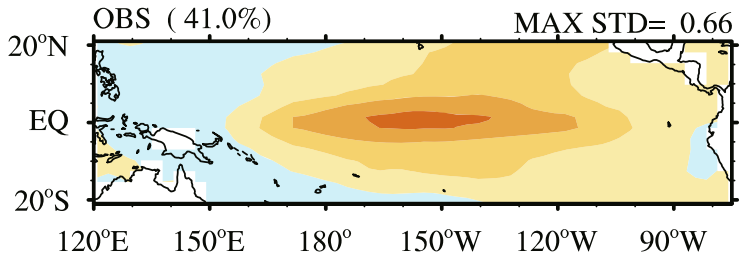

\section{(b) EP-ENSO}

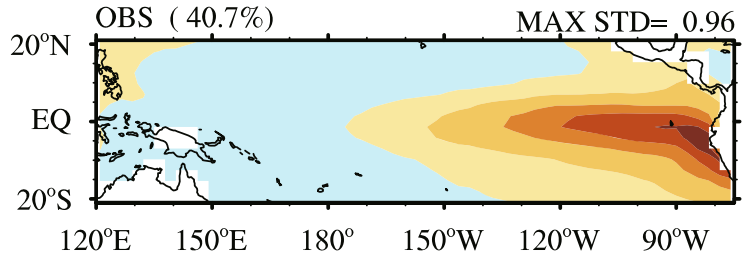

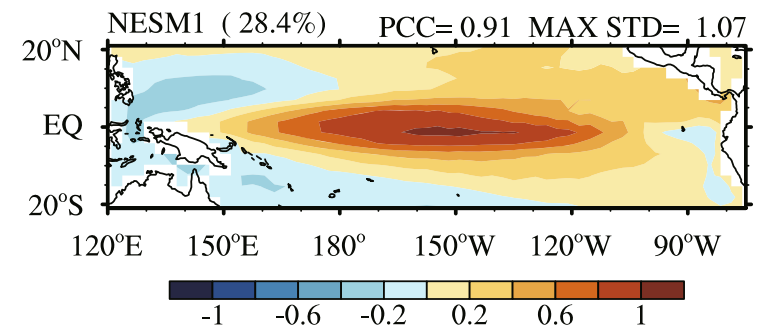

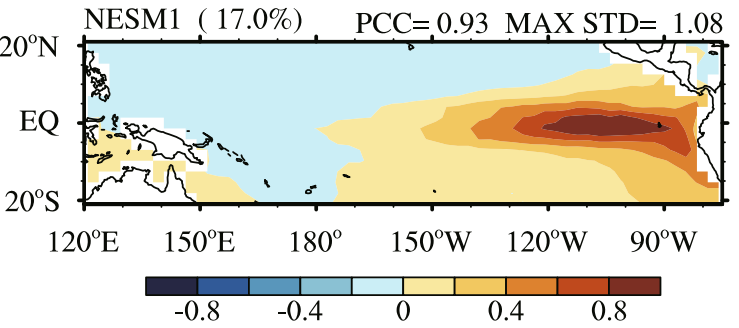

Fig. 6. The spatial patterns of the leading EOF modes for the (a) central Pacific (CP) and (b) eastern Pacific (EP) types of ENSO obtained from observation (top) and NESM1 (bottom). The loading coefficients for EOFs are scaled by the square root of their corresponding eigenvalues to represent the standard deviations (STD) of each EOF mode. Maximum Standard Deviation (MAX STD) is indicated in the top-right corner of all panels. The PCC between observed and simulated patterns is indicated in the top-right corner of the bottom panels. 
(a) Leading S-EOF modes of the AAM precipitation

OBS ( $20.7 \%)$
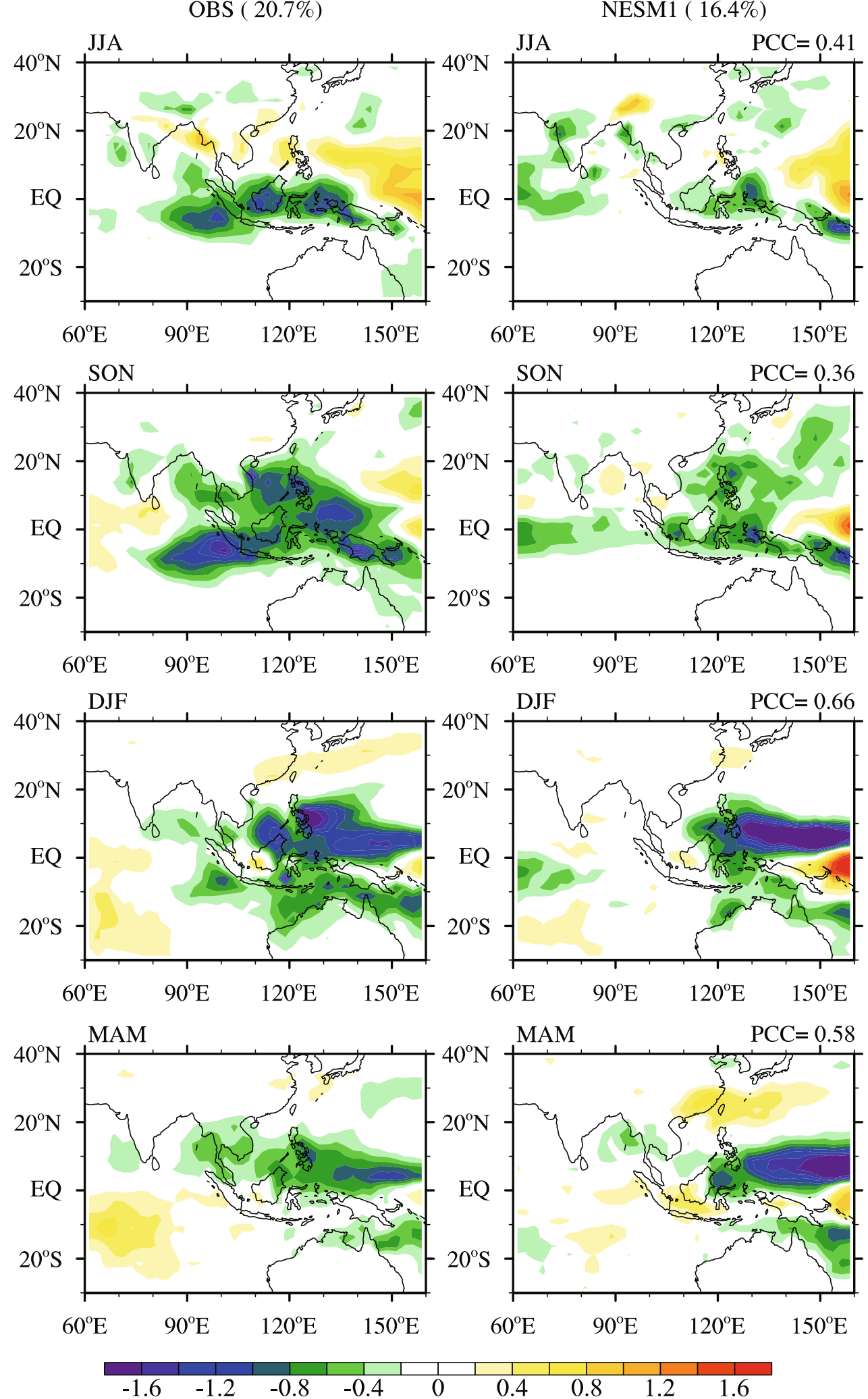

Fig. 7. (a) Spatial patterns of the first S-EOF modes of the Asian-Australian monsoon (AAM) precipitation obtained from observation (left) and NESM1 (T159) (right). The PCC between observed and simulated patterns is indicated in the top-right corner of the right-hand panels. (b) Lead-lag correlation coefficients of Niño3.4 SST index with reference to the first S-EOF principal component obtained from observation and NESM1 (T159). 
(b) Lead-lag correlation coefficients

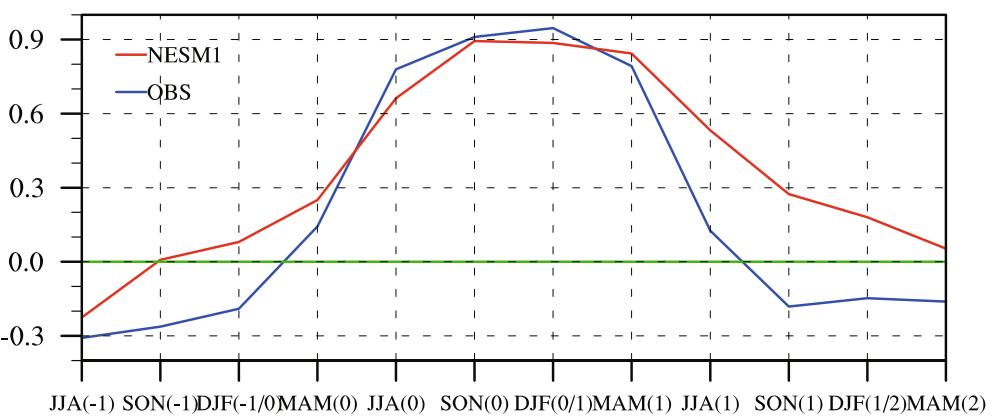

Fig. 7. (Continued.)

of AAM precipitation in comparison with POEM2 and 20 CMIP5 CGCMs. NESM1 is among the top models, especially for simulating the precipitation variance. Compared with NESM1 (T42), NESM1 (T159) shows great improvements in terms of simulating the AAM, which is also better than 14 out of the 20 CMIP5 models.

\subsection{ISO/MJO}

We first evaluate the model's performance based on variance of 20-100-day bandpass filtered precipitation. The model can capture well the ISO variability in precipitation and the $850 \mathrm{hPa}$ zonal wind (U850) during both boreal winter (NDJFMA) $(\mathrm{PCC}=0.74$ for precipitation, $\mathrm{PCC}=0.85$ for $\mathrm{U} 850$ ) and boreal summer (MJJASO) ( $\mathrm{PCC}=0.78$ for precipitation and $\mathrm{PCC}=0.85$ for U850) (figure not shown). The model also reproduces reasonably well the precipitation variability during MJJASO over the western North Pacific and East Asian region, but tends to overestimate the variance over the western Pacific in NDJFMA.

In order to isolate the characteristic spatial and temporal scales on which the intraseasonal variability is organized, we present in Fig. 9 the equatorial (averaged over $10^{\circ} \mathrm{S}-10^{\circ} \mathrm{N}$ ) wavenumber-frequency spectra of precipitation and $850 \mathrm{hPa}$ zonal wind. From observation, the precipitation spectrum shows energy concentration between zonal wave numbers 1 and 3 and periods between 30 and 70 days with a spectral peak at around 40 days. These scales distinguish the MJO from other convectively coupled equatorial waves (Wheeler and Kiladis, 1999). NESM1 shows that the energy is concentrated on a time scale longer than 80 days and a shorter spatial scale of zonal wave number 2-4 for precipitation. These biases mean that the simulated MJO has considerably slow eastward propagation. The spectral power of equatorial 850 $\mathrm{hPa}$ zonal winds also shows stronger low-frequency variability longer than 80 days, while the dominant zonal wave number is $1-2$, as in the observations (Fig. 9d).

The commonly used metrics to measure ISO/MJO skill are the Real-time Multivariate MJO (RMM) index (Wheeler and Hendon, 2004), which is based on the nature of ISO/MJO with convection coupling with baroclinic circulations. In Fig. 10, we evaluate the model's performance in capturing the first two multivariate EOF modes of 20-100-day variations in U850, $200 \mathrm{hPa}$ zonal wind (U200), and OLR

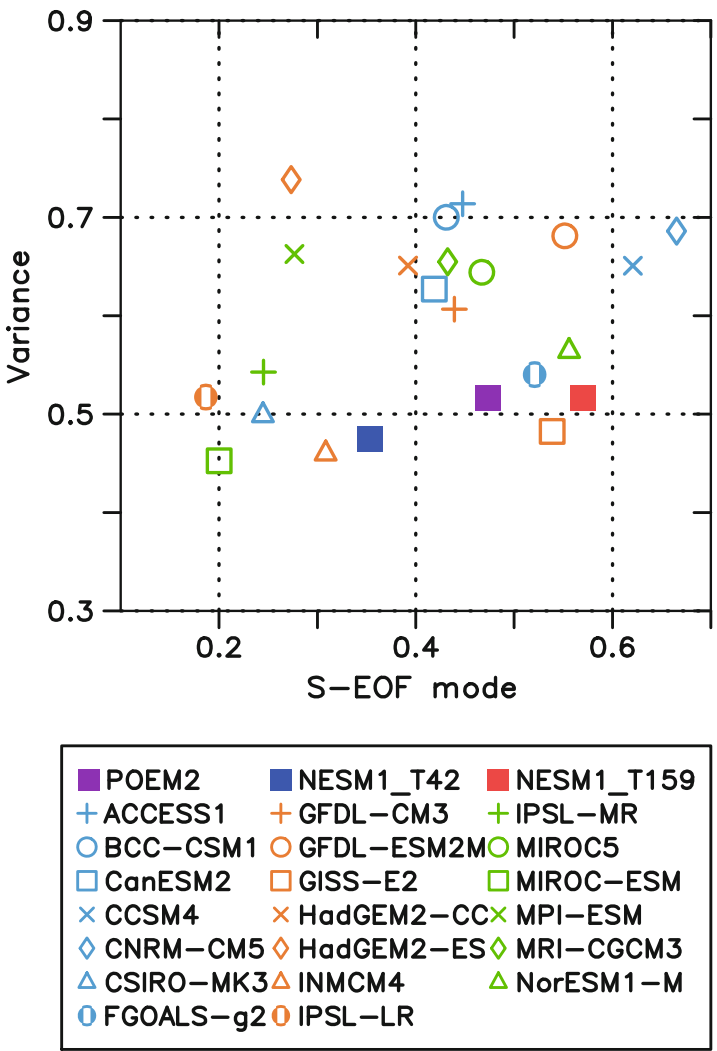

Fig. 8. The season-averaged PCC for the first S-EOF mode of AAM precipitation (abscissa) and the PCC skill for variance (ordinate) of precipitation in JJA simulated by NESM1 (T42 and T159), POEM2 and 20 CMIP5 CGCMS.

averaged between $15^{\circ} \mathrm{S}$ and $15^{\circ} \mathrm{N}$ (Wheeler and Hendon, 2004). Together, these two modes constitute the eastward propagating MJO and explain about $40 \%$ of the filtered variance (Fig. 10a), and they also represent the first two leading predictable modes of MJO. The upper- and lowertroposphere zonal winds are out of phase, thus demonstrating the baroclinic structure of the MJO. There is a signal displacement of the zonal wind maxima relative to the convection signal with low-level easterlies (westerlies) tending to lead (trail) the convection maximum. NESM1 captures the OLR-circulation structure very well for both modes, except 
(a) Precipitation
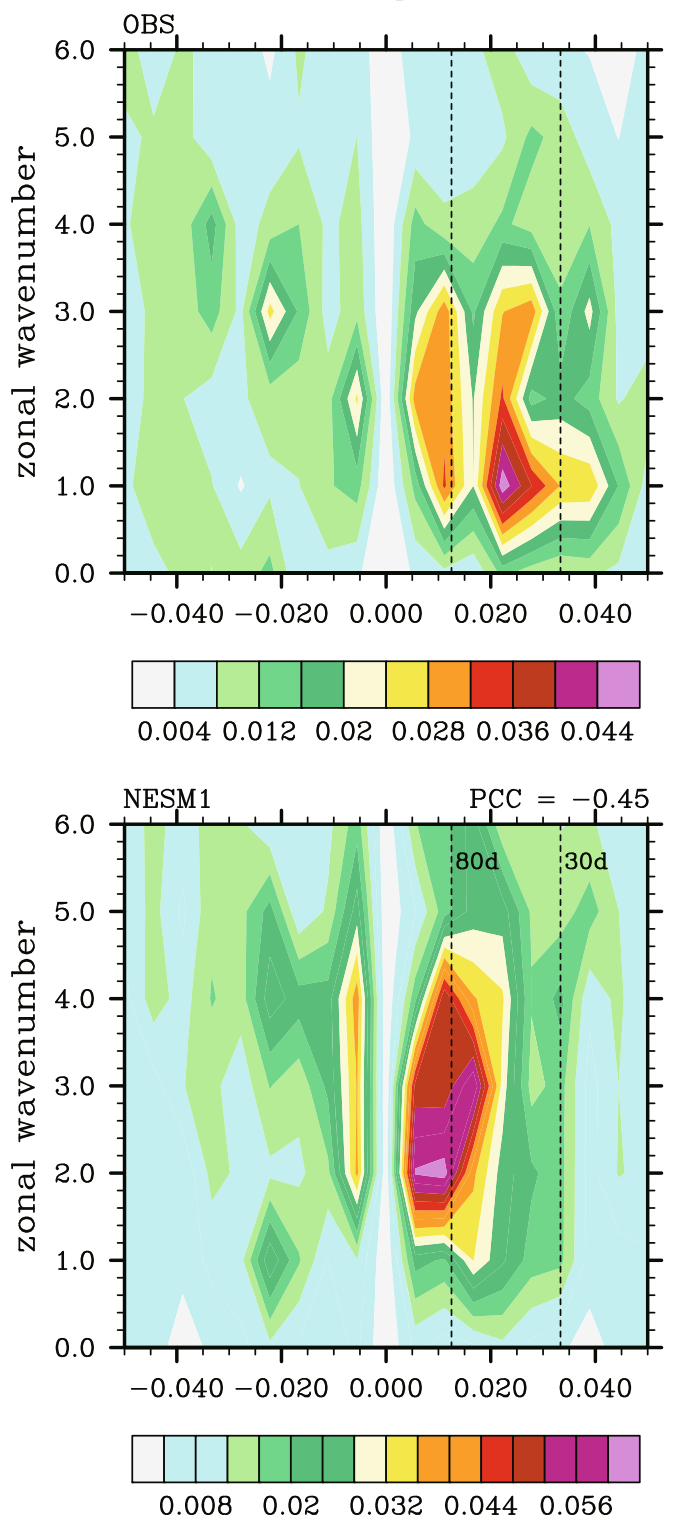

(b) U850
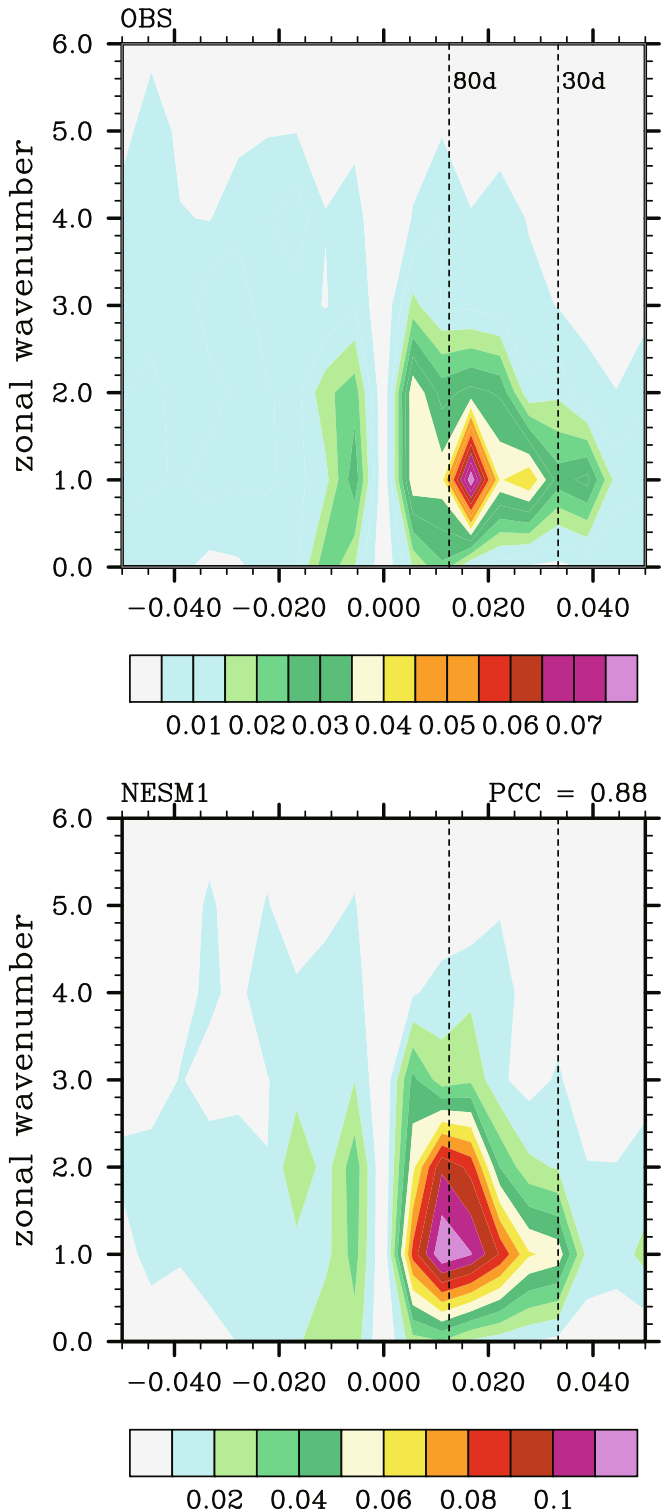

Fig. 9. The wavenumber-frequency spectra of $10^{\circ} \mathrm{S}-10^{\circ} \mathrm{N}$ averaged (a) precipitation and (b) zonal wind at 850hPa (U850) during NDJFMA from observation (upper panel) and NESM1 (lower panel). The PCC between observed and simulated patterns for precipitation and zonal wind at $850 \mathrm{hPa}$ over wavenumbers 1-3 and a period of 30-80 days are indicated in the top-right corner of the bottom panels.

for a westward shift of the minimum OLR in RMM2. The main weakness is that the simulated fractional variance of the RMM1 (14\%) is significantly lower than the observed counterpart $(20 \%)$, indicating that the model underestimates MJO activity over the Indian Ocean.

Figure 10b presents the lead-lag correlation structures between the RMM1 and RMM2 time coefficients from observation and NESM1. The positive correlation at negative time lag (-10 days) is an indication that the RMM1 leads RMM2, consistent with enhanced convection (negative OLR anomalies) propagating from the Indian Ocean to the western Pacific. NESM1 simulates the lead-lag correlation structure extremely well. From observation (NESM1), the maximum correlation is about $0.79(0.65)$ at the 9-day (10-day) lead. However, since there is a westward shift of the minimum OLR in RMM2, the realistic lead-lag correlation between the two modes alone does not mean the propagation speed is correct. In fact, the spatial structural bias in RMM2 implies a slow eastward propagation, consistent with what we have seen from the wavenumber-frequency diagnostics.

\section{Summary}

A new coupled ESM, named NESM1, has been developed at NUIST, which employs the component models of ECHAM (v5.3), NEMO (v3.4) and CICE (v4.1), coupled by 
(a) Multivariate EOF modes
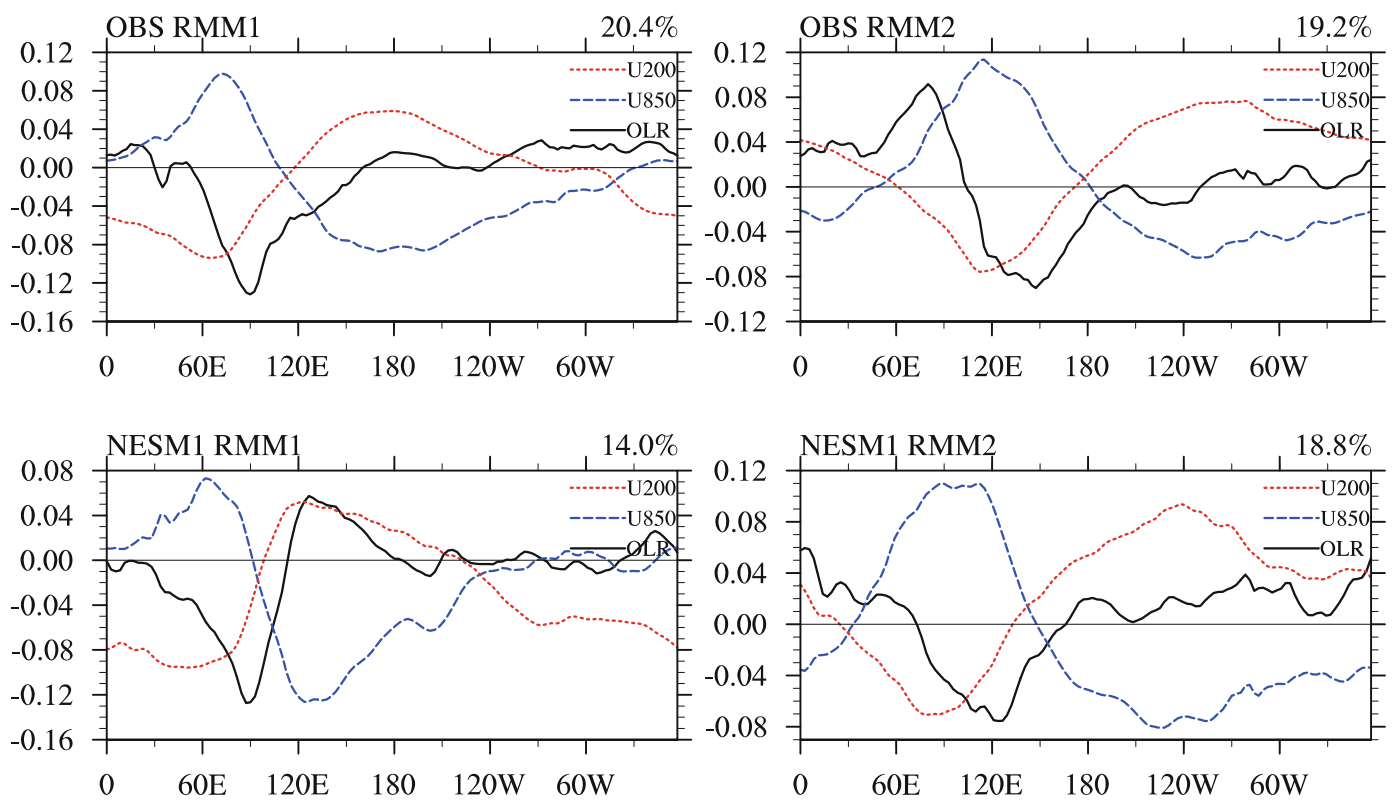

(b) Lead-lag correlation coefficients

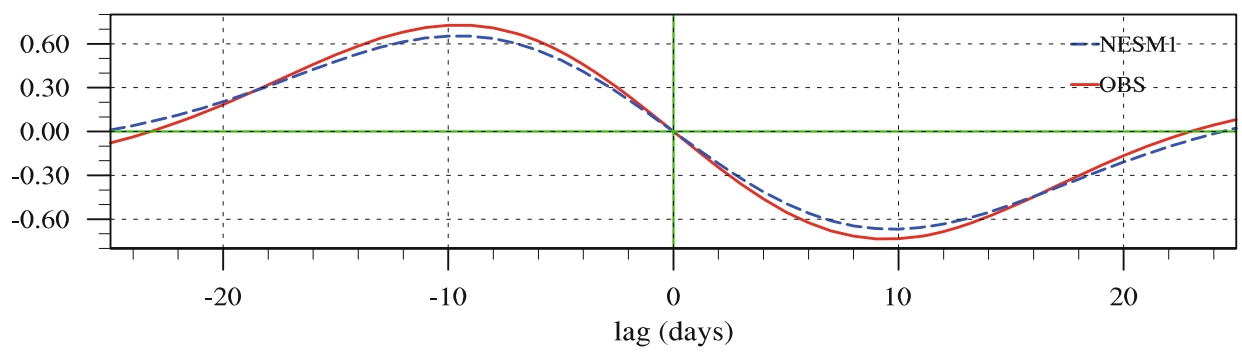

Fig. 10. (a) The first two multivariate EOF modes (RMM1 and RMM2) of 20-100-day bandpass filtered U850, U200 and OLR averaged over $15^{\circ} \mathrm{S}-15^{\circ} \mathrm{N}$ from observation (top) and NESM1 (bottom) over all seasons. (b) Lead-lag correlations of PC1 and PC2 over all seasons with positive correlation at negative time lags corresponding to RMM1 leading RMM2 (Indian Ocean convection leading Maritime Continent convection) from observation and NESM1.

the OASIS3-MCT parallel coupler. Model outputs from free coupled runs were evaluated in terms of forced response (annual cycle) and internal feedback modes (ENSO, monsoon, and ISO). The quantitative measures used to judge the level of success were the PCC and NRMSE. The results are presented in Table 1. The major strengths and weaknesses of NESM1, as well as plans for future improvement, are summarized as follows:

(1) Annual mean and annual cycle. NESM1 reproduces the annual mean SST very well $(\mathrm{PCC}=0.95)$, especially in the equatorial oceans. The annual cycle of the equatorial SST is also well simulated ( $\mathrm{PCC}=0.86$ ), except a moderate delay of maximum warming in the eastern Pacific (Fig. 1a). These successes help the model's simulation of ENSO. The simulated mean precipitation is reasonably good $(\mathrm{PCC}=0.81)$, but suffers from the double ITCZ problem (Fig. 2a). The model reproduces the observed first annual cycle (solstice) mode reasonably realistically $(\mathrm{PCC}=0.78)$, but has difficulty in capturing the second annual cycle (equinox) mode (PCC
$=0.58)($ Figs. 2b and c). NESM1 (T159) reproduces the GM precipitation intensity reasonably well (PCC $=0.82$ ) (Fig. 3 ), but underestimates the intensity over the East Asian monsoon regions and overestimates the intensity over the tropical ocean.

(2) ENSO. The ENSO mode simulated by NESM1 is more impressive than other modes. NESM1 captures very well the following features: the spatial structure of the dominant EOF mode of SST variability over the tropical Pacific in DJF (PCC = 0.89); the ENSO phase locking to the annual cycle, with a maximum peak in November-January; the spectrum of the Niño3 SST anomaly, with major peaks at 2 years and 4-5 years; and the spatial structures of the CP-ENSO $(\mathrm{PCC}=0.91)$ and EP-ENSO $(\mathrm{PCC}=0.93)($ Figs. 5 and 6). Overall, the performance of NESM1 with respect to ENSO is among the top third of CMIP5 models (Fig. 4). However, the simulated equatorial SST variability is too strong and shows a significant westward shift. The biennial component of ENSO (Fig. 5c) and the amplitude of CP-ENSO (Fig. 6a) are over- 
estimated.

(3) Monsoon variability. NESM1 (T159) is among the top CMIP5 models in reproducing the observed major precipitation variability patterns for JJA $(\mathrm{PCC}=0.79$, NRMSE $=0.95)$ and DJF $(\mathrm{PCC}=0.79, \mathrm{NRMSR}=0.79)$. Moreover, the model simulates the monsoon-ENSO lead-lag correlation very well, and also simulates the spatial structures of the leading S-EOF modes of the AAM rainfall variability reasonably well (averaged PCC $=0.51$ ) (Fig. 7), which is better than 14 out of 20 CMIP5 models (Fig. 8).

(4) ISO/MJO. NESM1 captures well the spatial patterns of the MJO and boreal summer intraseaonal oscillation (BSISO) variability, particularly for U850 during both boreal winter and boreal summer $(\mathrm{PCC}=0.85)$, although the model simulates slower than observed MJO propagation speed. The first two leading predictable MJO modes, RMM1 and RMM2, are captured realistically (Fig. 10), implying that the model reproduces very well the vertical and zonal structure of the coupled convection and circulation, except that the simulated fractional variance of RMM1 is only two thirds of its observed counterpart, indicating that the model underestimates MJO activity over the Indian Ocean.

The performance of NESM1 was also compared with 20 coupled models that participated in CMIP5. It was found that NESM1 is among the top models with respect to the spatial distribution of monthly SST variance, the dominant mode of DJF ENSO variability, the spatial structures of the leading SEOF modes of the AAM rainfall variability, and particularly for simulating the precipitation variance.

The results presented in this paper show that the overall performance of NESM1 is good, although some biases in model simulations need to be further addressed. Increasing the atmospheric model resolution seems mainly to affect the simulation of precipitation, improving the mean precipitation and interannual variability. The double ITCZ problem for precipitation is not well understood, despite plaguing many ESMs for a long time. The simulated MJO signal in NESM1 shows a slower eastward propagation than observation. These shortcomings may be related to aspects of convection parameterization. Therefore, while NESM1 is an established ESM framework, like all models it is subject to further developments. These developments will include improvements to the existing components, as well as implementation of new components, such as land dynamic vegetation and ocean biochemistry, atmospheric chemistry, and interactive aerosols.

Acknowledgements. We thank the support from NUIST and all colleagues at the Earth System Modeling Center who have contributed towards the development of the model. We also acknowledge support from the International Pacific Research Center, University of Hawaii. CAO Jian is also supported by the Research Innovation Program for college graduates of Jiangsu Province (CXLX13_487). Dr. Sun-Seon LEE offered help for plotting the comparison figures. This paper is the ESMC publication number 027 .

Open Access. This article is distributed under the terms of the
Creative Commons Attribution License which permits any use, distribution, and reproduction in any medium, provided the original author(s) and the source are credited.

\section{REFERENCES}

Annamalai, H., K. Hamilton, and K. R. Sperber, 2007: The south Asian Summer Monsoon and its relationship with ENSO in the IPCC AR4 simulation. J. Climate, 20, 1071-1092.

An, S.-I., and B. Wang, 2001: Mechanisms of locking of the El Niño and La Nina mature phases to boreal winter. J. Climate, 14, 2164-2176.

Ashok, K., S. Behera, A. S. Rao, H. Y. Weng, and T. Yamagata, 2007: El Ninõ Modoki and its teleconnection. J. Geophys. Res., 112, C11007, doi: 10.1029/2006JC003798.

Barnier, B., and Coauthors, 2006: Impact of partial steps and momentum advection schemes in a global ocean circulation model at eddy-permitting resolution. Ocean Dyn., 56, 543567.

Bengtsson, L., U. Schlese, E. Roeckner, M. Latif, T. P. Barnett, and N. E. Graham, 1993: A Two-tiered approach to Long-range climate forecasting. Science, 261, 1027-1029.

Cane, M., S. E. Zebiak, and S. C. Dolan, 1986: Experimental forecasts of El Ninõ. Nature, 321, 827-832.

Dai, Y. J., and Coauthors, 2003: The Common Land Model. Bull. Amer. Meteor. Soc., 84, 1013-1023.

Dai, Y. J., R. E. Dickinson, and Y.-P. Wang, 2004: A two-big-leaf model for canopy temperature, photosynthesis, and stomatal conductance. J. Climate, 17, 2281-2299.

Davey, M., and Coauthors, 2002: A study of coupled model climatology and variability in tropical ocean regions. Climate Dyn., 18, 403-420.

Ding, Q. H., E. J. Steig, D. S. Battisti, and M. Küttel, 2011: Winter warming in West Antarctica caused by central tropical Pacific warming. Nature Geoscience, 4, 398-403.

Ding, Y., Y. Ni, X. Zhang, W. Li, M. Dong, Z.-C. Zhao, Z. Li, and W. Shen, 2000: Introduction to the Short-term Climate Prediction Model System. China Meteorological Press, Beijing, China, 500 pp. (in Chinese)

Fouquart, Y., and B. Bonnel, 1980: Computations of solar heating of the earth's atmosphere: A new parameterization. Beiträge zur Atmosphärenphysik, 53, 35-62.

Gadgil, S., and S. Sajani, 1998: Monsoon precipitation in the AMIP runs. Climate Dyn., 14, 659-689.

Goswami, B. N., 1998: Interannual variations of Indian Summer Monsoon in a GCM: External conditions versus internal feedbacks. J. Climate, 11, 501-522.

Hazeleger, W., and Coauthors, 2010: EC-Earth: A seamless EarthSystem prediction approach in action. Bull. Amer. Meteor Soc., 91, 1357-1363.

Hewitt, H. T., D. Copsey, I. D. Culverwell, C. M. Harris, R. S. R. Hill, A. B. Keen, A. J. McLaren, and E. C. Hunke, 2011: Design and implementation of the infrastructure of HadGEM3: The next-generation Met Office climate modelling system. Geoscientific Model Development, 4, 223-253.

Huffman, G. J., R. F. Adler, D. T. Bolvin, and G. J. Gu, 2009: Improving the global precipitation record: GPCP Version 2.1. Geophys. Res. Lett., 36, L17808, doi: 10.1029/2009GL 040000.

Hunke, E. C., and W. H. Lipscomb, 2010: CICE: The Los Alamos Sea Ice Model Documentation and Software User's Manual 
Version 4.1. LA-CC-06-012, T-3 Fluid Dynamics Group, Los Alamos National Laboratory, Los Alamos N.M.

Ji, D., and Coauthors, 2014: Description and basic evaluation of BNU-ESM version 1. Geoscientific Model Development Discussions, 7, 1601-1647.

Kanamitsu, M., W. Ebisuzaki, J. Woollen, S.-K. Yang, J. J. Hnilo, M. Fiorino, and G. L. Potter, 2002: NCEP-DOE AMIP-II Reanalysis (R-2). Bull. Amer. Meteor. Soc., 83, 1631-1643.

Kao, H.-Y., and J.-Y. Yu, 2009: Contrasting Eastern-Pacific and Central-Pacific types of ENSO. J. Climate, 22, 615-632.

Kim, H.-M., P. J. Webster, and J. A. Curry, 2009: Impact of shifting patterns of Pacific Ocean warming on north Atlantic tropical cyclones. Science, 325, 77-80.

Larson, J., R. Jacob, and E. Ong, 2005: The model coupling toolkit: A new Fortran 90 toolkit for building multiphysics parallel coupled models. International Journal of High Performance Computing Applications, 19(3), 277-292.

Latif, M., and Coauthors, 2001: ENSIP: The El-Niño simulation intercomparison project. Climate Dyn., 18, 255-276.

Lau, N.-C., and M. J. Nath, 2000: Impact of ENSO on the variability of the Asian-Australian monsoons as simulated in GCM experiments. J. Climate, 13, 4287-4309.

Lee, J.-Y., and B. Wang, 2014: Future change of global monsoon in the CMIP5. Climate Dyn., 42, 101-119.

Lee, J.-Y., and Coauthors, 2010: How are seasonal prediction skills related to models' performance on mean state and annual cycle? Climate Dyn., 35, 267-283.

Lengaigne, M., G. Madec, L. Bopp, C. Menkes, O. Aumont, and P. Cadule, 2009: Bio-physical feedbacks in the Arctic Ocean using an Earth system model. Geophys. Res. Lett., 36, L21602. doi: 10.1029/2009GL040145.

Le Sommer, J., T. Penduff, S. Theetten, G. Madec, and B. Barnier, 2009: How momentum advection schemes influence currenttopography interactions at eddy permitting resolution. Ocean Modelling, 29(1), 1-14.

Liebmann, B., and C. A. Smith, 1996: Description of a complete (interpolated) outgoing longwave radiation dataset. Bull. Amer. Meteor. Soc., 77, 1275-1277.

Liu, L., G. Yang, B. Wang, C. Zhang, R. Li, Z. Zhang, Y. Ji, and L. Wang, 2014: C-Coupler1: A Chinese community coupler for Earth system modelling. Geoscientific Model Development Discussions, 7, 3889-3936.

Lohmann, U., and E. Roeckner, 1996: Design and performance of a new cloud microphysics scheme developed for the ECHAM general circulation model. Climate Dyn., 12, 557-572.

Madec, G., and the NEMO team, 2012: NEMO ocean engine. Note du ple de modélisation, No 27, Institut Pierre-Simon Laplace (IPSL), France.

Madec, G., P. Delecluse, M. Imbard, and C. Levy, 1998: OPA 8.1 ocean general circulation model-reference manual. Tech. Rep., LODYC/IPSL Note 11, Institut Pierre-Simon Laplace (IPSL), France, $91 \mathrm{pp}$.

Manabe, S., and K. Bryan, 1969: Climate calculation with a combined ocean-atmosphere model. J. Atmos. Sci., 26, 786-789.

Mechoso, C. R., and Coauthors, 1995: The seasonal cycle over the Tropical Pacific in Coupled Ocean-Atmosphere General Circulation Models. Mon. Wea. Rev., 123, 2825-2838.

Mitchell, T. P., and J. M. Wallace, 1992: On the annual cycle in equatorial convection and sea surface temperature. J. Climate, $\mathbf{5}, 1140-1156$

Mlawer, E. J., S. J. Taubman, P. D. Brown, M. J. Iacono, and S. A. Clough, 1997: Radiative transfer for inhomogeneous atmo- spheres: RRTM, a validated correlated-k model for the longwave. J. Geophys. Res., 102, 16663-16682.

Nigam, S., and Y. Chao, 1995: On the evolution of the tropical ocean-atmosphere annual-cycle. TOGA Notes, 18, Nova University Press, $12-16$.

Qiao, F. L., Z. Y. Song, Y. Bao, Y. J. Song, Q. Shu, C. J. Huang, and W. Zhao, 2013: Development and evaluation of an Earth System Model with surface gravity waves. J. Geophys. Res.: Oceans, 118, 514-4524.

Roeckner, E., and Coauthors, 2003: The atmospheric general circulation model ECHAM5. Part I: Model description. Rep. No. 349, Max-Planck-Institut für Meteorologie, Hamburg, Germany, $127 \mathrm{pp}$.

Saji, N. H., and T. Yamagata, 2003: Possible impacts of Indian Ocean Dipole mode events on global climate. Climate Res., 25, 151-169.

Smith, T. M., and R. W. Reynolds, 2004: Improved extended reconstruction of SST (1854-1997). J. Climate, 17, 2466-2477.

Sperber, K. R., and T. N. Palmer, 1996: Interannual tropical rainfall variability in general circulation model simulations associated with the atmospheric model intercomparison project. $J$. Climate, 9, 2727-2750.

Tiedtke, M., 1989: A comprehensive mass ux scheme for cumulus parameterization in largescale models. Mon. Wea. Rev., 117, 1779-1800.

Turner, A. G., P. M. Inness, and J. M. Slingo, 2005: The role of the basic state in the ENSO-monsoon relationship and implications for predictability. Quart. J. Roy. Meteor. Soc., 131, 781-804.

Vitart, F., W. Robertson, and D. L. T. Anderson, 2012: Subseasonal to Seasonal Prediction Project: Bridging the gap between weather and climate. WMO Bulletin, 61(2), 23-28.

Waliser, D. E., 2011: Predictability and forecasting. Intraseasonal Variability in the Atmosphere-Ocean Climate System, 2nd ed., W. K. M. Lau and D. E. Waliser, Eds., Springer, 433-476.

Waliser, D., and Coauthors, 2009: MJO simulation diagnostics. J. Climate, 22, 3006-3030.

Wang, B., and S.-I. An, 2005: A method for detecting seasondependent modes of climate variability: S-EOF analysis. Geophys. Res. Lett., 32, L15710, doi: 10.1029/2005GL 022709.

Wang, B., and Q. H. Ding, 2008: Global monsoon: Dominant mode of annual variation in the tropics. Dyn. Atmos. Oceans, 44, 165-183.

Wang, B., R. G. Wu, and X. H. Fu, 2000: Pacific-East Asia teleconnection: How does ENSO affect East Asian climate? $J$. Climate, 13, 1517-1536.

Wang, B., I.-S. Kang, and J.-Y. Lee, 2004: Ensemble simulations of Asian-Australian Monsoon variability by 11 AGCMs. $J$. Climate, 17, 803-818.

Wang, B., Q. H. Ding, X. H. Fu, I.-S. Kang, K. Jin, J. Shukla, and F. Doblas-Reyes, 2005: Fundamental challenge in simulation and prediction of summer monsoon rainfall. Geophys. Res. Lett., 32, L15711, doi: 10.1029/2005GL022734.

Wang, B., J. Yang, T. J. Zhou, and B. Wang, 2008a: Interdecadal changes in the major modes of Asian-Australian monsoon variability: Strengthening relationship with ENSO since the late 1970s. J. Climate, 21, 1771-1789, doi: 10.1175/ 2007JCLI1981.1.

Wang, B., and Coauthors, 2008b: How accurately do coupled climate models predict the leading modes of Asian-Australian monsoon interannual variability? Climate Dyn., 30, 605-619. 
Wang, B., and Coauthors, 2009: Advance and prospect of seasonal prediction: Assessment of the APCC/CliPAS 14-model ensemble retroperspective seasonal prediction (1980-2004). Climate Dyn., 33, 90-117.

Wang, B., H. J. Kim, K. Kikuchi, and A. Kitoh, 2011: Diagnostic metrics for evaluation of annual and diurnal cycles. Climate Dyn., 37, 941-955.

Wang, B., J.-Y. Lee, and B. Xiang, 2014: Asian summer monsoon rainfall predictability: A predictable mode analysis. Climate Dyn., doi: 10.1007/s00382-014-2218-1.

Wheeler, M., and G. N. Kiladis, 1999: Convectively coupled equatorial waves: Analysis of clouds and temperature in the wavenumber-frequency domain. J. Atmos. Sci., 56, 374-399.

Wheeler, M. C., and H. H. Hendon, 2004: An All-season Realtime multivariate MJO index: Development of an index for monitoring and prediction. Mon. Wea. Rev., 132, 1917-1932.

Xiang, B. Q., B. Wang, Q. H. Ding, F.-F. Jin, X. H. Fu, and H.-J. Kim, 2012: Reduction of the thermocline feedback associated with mean SST bias in ENSO simulation. Climate Dyn., 39,
$1413-1430$

Xiang, B. Q., B. Wang, and T. Li, 2013: A new paradigm for the predominance of standing Central Pacific Warming after the late 1990s. Climate Dyn., 41(2), 327-340.

Yeh, S.-W., J.-S. Kug, B. Dewitte, M.-H. Kwon, B. Kirtman, and F.-F. Jin, 2009: El Ninõ in a changing climate. Nature, 461, 511-514, doi: 10.1038/nature08316.

Yu, Y. Q., and Coauthors, 2008: Coupled model simulations of climate changes in the 20th century and beyond. Adv. Atmos. Sci., 25(4), 641-654, doi: 10.1007/s00376-008-0641-0.

Zalesak, S. T., 1979: Fully multidimensional flux corrected transport algorithms for fluids. J. Comput. Phys., 31, 335-362.

Zebiak, S. E., and M. A. Cane, 1987: A model El-Niño-Southern Oscillation. Mon. Wea. Rev., 115, 2262-2278.

Zhang, C. D., J. Gottschalck, E. D. Maloney, M. W. Moncrieff, F. Vitart, D. E. Waliser, B. Wang, and M. C. Wheeler, 2013: Cracking the MJO nut. Geophys. Res. Lett., 40, 1223-1230, doi: $10.1002 /$ grl.50244. 